\title{
MEASURING THE UNIAXIAL GOMPRESSIVE STRENGTH OF ICE
}

\author{
By F. D. Haynes and M. Mellor \\ (U.S. Army Cold Regions Research and Engineering Laboratory, Hanover, New \\ Hampshire 03755, U.S.A.)
}

\begin{abstract}
An attempt was made to develop a simple but accurate method for making compressive strength tests on right circular cylinders. Compliant loading platens were designed to apply uniform normal stress without introducing significant interface radial shear stresses. The compliant platens gave reproducible results that agree well with results obtained by a precise conventional technique. Accurate results were obtained with simple specimen preparation, and with short specimens where the length-todiameter ratio was less than unity. Platens were made from a rubber-like urethane which was molded in aluminum cylinders to provide lateral restraint. Uniaxial compression tests on cylindrical polycrystalline ice specimens were made to determine the characteristics of the platens. For 2I specimens with ends prepared on a lapping plate to obtain a mirror finish, the measured strength showed a variation of only $13 \%$ for lengthto-diameter ratios from 0.74 to 2.5 , with no systematic trend. Another 2 I specimens with length-to-diameter ratios of about 2.35 were tested with various platens and various methods of specimen end preparation. The strength for specimens with saw-cut ends and for those with ends lapped showed very little difference when tested with the rubber platens.
\end{abstract}

RÉsumé. Mesures de la résistance de la glace à une compression uniaxiale. On a essayé de mettre au point une méthode simple mais précise pour exécuter des essais de résistance à la compression dans des cylindres circulaires droits. On a conçu des plateaux souples chargés pour produire un effort uniforme sans introduire de cisaillement radial significatif à l'interface. Les plateaux souples donnent des résultats reproductibles qui concordent bien avec ceux obtenus par des techniques conventionnelles précises. Des résultats précis peuvent être obtenus avec la préparation d'échantillons simples et sur des échantillons courts où le rapport de la longueur au diamètre est inférieur à l'unité. Les plateaux étaient faits en une sorte de gomme en urethane qui était moulée dans des cylindres en aluminium pour les limiter latéralement. Des essais de compression uniaxiales sur des échantillons de glace polycristalline cylindrique ont été faits pour déterminer les caractéristiques des plateaux. Pour 2 I échantillons dont les extrémités étaient préparées sur une assiette à polir pour obtenir une finition équivalente à celle d'un miroir, les résistances mesurées montrèrent une variation de seulement $13 \%$ pour des rapports longueur/diamètre allant de 0,74 à 2,5 sans erreur systematique décelable. Vingt et un autres échantillons avec des rapports longeur/diamètre d'environ 2,35 furent essayés avec différents plateaux et différents modes de préparation des extrémités. Les résistances mesurées sur les échantillons coupés à la scie et sur ceux soigneusement polis ne montraient que de très faibles différences lorsque les mesures étaient faites avec les plateaux en gomme.

Zusammenfassung. Messung der einachsialen Druckfestigkeit von Eis. Es wurde versucht, eine einfache, aber genaue Methode für Druckfestigkeitsversuche an geraden Kreiszylindern zu entwickeln. Geeignete Anpressplatten wurden entworfen, die einen gleichmässigen Normaldruck erzeugen sollten, ohne dass merkliche radiale Scherspannungen an den Berührflächen aufträten. Die Platten lieferten reproduzierbare Ergebnisse, die gut mit solchen übereinstimmen, die mit der herkömmlichen Präzisionstechnik gewonnen wurden. Genaue Resultate lassen sich mit einfacher Bearbeitung der Proben und mit kurzen Proben, deren Länge unterhalb ihres Durchmessers liegt, erzielen. Die Platten bestehen aus einem gummiartigen Urethan, das zur seitlichen Fassung in Aluminium-Zylinder gegossen wurde. Einachsige Druckversuche mit zylindrischen polykristallinen Eisproben wurden zur Bestimmung der Plattencharakteristiken vorgenommen. Bei 2 I Proben mit Endflächen, die spiegelartig präpariert waren, schwankte die gemessene Festigkeit nur um $13 \%$ bei Verhältnissen zwischen Länge und Durchmesser von 0,74 bis 2,5, und zwar ohne erkennbare Systematik. Weitere 2 I Proben mit Länge und Durchmesser-Verhältnissen von etwa 2,35 wurden mit verschiedenen Platten und verschiedenen Methoden zur Bearbeitung der Endflächen getestet. Die Festigkeit der Proben mit gesägten Endflächen unterschied sich bei Versuchen mit den Gummiplatten nur wenig von der Festigkeit bei spiegelglatten Endflächen.

\section{INTRODUCTION}

In principle, the uniaxial compressive strength of a solid material is easy to measure. Uniform uniaxial stress is induced in a cylinder or prism of the material and is increased steadily at either a constant strain-rate or a constant stress-rate; the peak stress developed at failure is taken as the uniaxial compressive strength under the prevailing test conditions. In reality, however, uniaxial compressive strength is not easy to measure, since it is very difficult to induce a state of true uniaxial stress. These matters are treated at length by Hawkes and Mellor (1970). 
In the conventional test, axial force is applied to the ends of a right circular cylinder through steel platens which make direct contact with the test specimen. Friction between the platens and the specimen produces radial restraint so that there is a triaxial state of stress near the end planes of the specimen; the triaxial field is significant over an axial distance of about one specimen radius from the end planes. The introduction of a highly compliant sheet (elastic or plastic) between platen and specimen often changes the sign of radial end forces, but does not eliminate the triaxial stress field. On a different scale, irregularities in the specimen end planes also create localized stress perturbations, and in brittle material these commonly initiate the microcracks that lead to premature failure of the specimen. Further stress gradients can be produced by eccentric loading and by lack of parallelism between specimen end planes or between end planes and loading platens.

In tests that lead to brittle fracture these are serious problems, and they are not easily solved. Since most attempts at solution have proved unsuccessful or impracticable, the usual procedure is to accept positive frictional restraint at the specimen end planes and to use a specimen that is long enough to provide a mid-section that is reasonably free from stress perturbations due to the ends. Extreme care is exercised in specimen preparation to produce end planes that are normal to the axis of symmetry and flat within strict tolerances. A very thin sheet of compressible material (e.g. paper) may be placed between specimen and platens to compensate for very small surface irregularities, and a "locking" spherical seat of suitable design may be used to compensate for small departures from parallelism. Flexure and cracking of the specimen are avoided by strict alignment procedures and by provision of high rigidity in the loading device to avoid rotation or lateral translation of the platens.

This type of procedure has proved acceptable for high-quality laboratory tests on materials such as rocks, ceramics, and concrete. However, these materials are quite stable in typical test environments, in contrast with ice, which is usually tested at very high homologous temperatures.

When ice is tested at temperatures above $-15^{\circ} \mathrm{C}$ or so, it seems to be extremely difficult to obtain valid results with the conventional uniaxial compression test, even when great care is exercised. Hawkes and Mellor (1972) took exaggerated care in the preparation and testing of right circular cylinders, but at high loading rates they were unable to achieve strength values that approached those measured on specially designed dumb-bell specimens. As a result of such studies on testing technique, Mellor was forced to discard his own data that had been obtained earlier by methods long accepted at CRREL. It seems quite possible that some of the data recorded in the literature suffers from similar gross errors.

In field work in cold regions, it may be unrealistic to seek a solution through fanatical quality control since test quality is often below the standards that are attainable in a research laboratory. The laboratory alternative of using precisely formed dumb-bell specimens may also be impracticable for field operations, especially when tests have to be made on broken material obtained by inexpert core drilling. An attempt has therefore been made to develop an entirely new technique that is capable of giving accurate results with simple equipment under field conditions.

\section{Compliant platens}

The ideal way to load a specimen in uniaxial compression would be to apply hydrostatic pressure to the ends of the specimen by means of a fluid that cannot transmit shear stress. This does not appear to be practicable, but it is possible to use compliant solids. The objective is to apply axial normal force through a deformable material that conforms to the shape of the specimen end plane but at the same time to avoid any significant radial stress.

Theoretically, the required result could be obtained by pressing the specimen between platens that have a lower modulus than the specimen but which undergo a radial strain exactly 
equal to that of the specimen. When specimen and platen have the same diameter, the condition for the radial strains to be equal is that Young's modulus divided by Poisson's ratio should have the same value for both specimen and platen materials. Thus, if the platen is to have a modulus significantly lower than that of the specimen, it will also need to have a Poisson's ratio that is proportionately low; this does not seem to be a practical proposition.

A more reasonable alternative is to use a low-modulus solid that is laterally confined to prevent gross radial deformation. This approach was pioneered by Kartashov and others (1970), who made a compliant platen for rock testing by inserting a low-modulus plug into an open-ended steel cylinder, and by pre-loading it using a screw-in steel plug. With this arrangement, they found that the apparent strength did not vary with the length-to-diameter ratio $(L / D)$ of the specimen over a range of approximately 0.5 to 3 .

A low-modulus plug was cast inside an aluminum cylinder as an adaptation of the technique of Katashov and others for ice tests (Fig. I). To prevent extrusion of the insert, the inside diameter of the confining cylinder was slightly greater (of the order of o.I mm) than the diameter of the test specimen at failure (allowing for radial strain). The insert itself was a cast urethane which is similar in mechanical properties to hard rubber. The surface of the insert was faced-off in a lathe with a sharp tool to ensure that it was flat and normal to the axis of the confining cylinder. The notes that follow describe tests that were conducted to validate the performance of compliant platens.

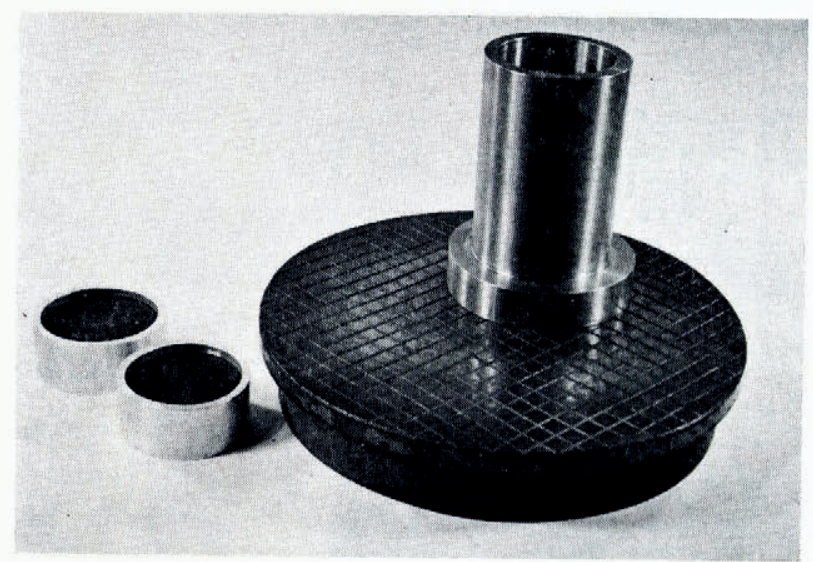

Fig. I. The lapping plate, the steel polishing jig, and the platens.

\section{SPECIMEN PREPARATION}

Twenty-one specimens were made for each series of tests using the following procedure. A "Lucite" mold was assembled by placing sleeves into its holes (the holes were $0.178 \mathrm{~m}$ long and $0.076 \mathrm{~m}$ in diameter) and then attaching a base-plate to the mold. Silicone grease was smeared lightly on the outside of the sleeves to facilitate removal of the specimens after they had been frozen. 2I of the 25 holes in the mold were filled with crushed ice from a commercial ice maker. A water passage was provided between the aluminum baseplate and the mold by the use of a wire-mesh spacer. Distilled, de-aired water was poured into one of the empty holes until the ice-filled holes were completely saturated.

To provide unidirectional freezing, insulation was placed on all sides of the mold except the bottom. The specimens were frozen by placing the mold in a cold room for $20 \mathrm{~h}$ at $-\mathrm{I} 5{ }^{\circ} \mathrm{C}$. The specimens were subsequently removed from the mold and stored in a cold room at $-7^{\circ} \mathrm{C}$ until required for testing. 
The ice tested in this study had an average grain size of about $\mathrm{I} \mathrm{mm}$, an average bubble size of approximately $0.4 \mathrm{~mm}$ and a density of $0.907 \mathrm{Mg} \mathrm{m}^{-3}$. A melt-water conductivity of $7 \times 10^{-4} \Omega^{-1} \mathrm{~m}^{-1}$ was measured at $23^{\circ} \mathrm{C}$.

For the series $\mathrm{I}$ and series 3 tests, the specimens were cut to varying lengths so as to give the desired length-to-diameter ratios. They were then placed in the steel polishing jig, shown in Figure I with the lapping plate, and lapped until a mirror finish was obtained.

In the series 2 tests, the specimen length was kept approximately constant with a $L / D$ ratio of $\approx 2.35$. About half of the specimens were prepared with lapped ends as described above, the other half were cut accurately with a hand mitre saw. Rubber membranes were then placed on the specimens and they were stored in plastic bags in an ice-saturated atmosphere to minimize sublimation.
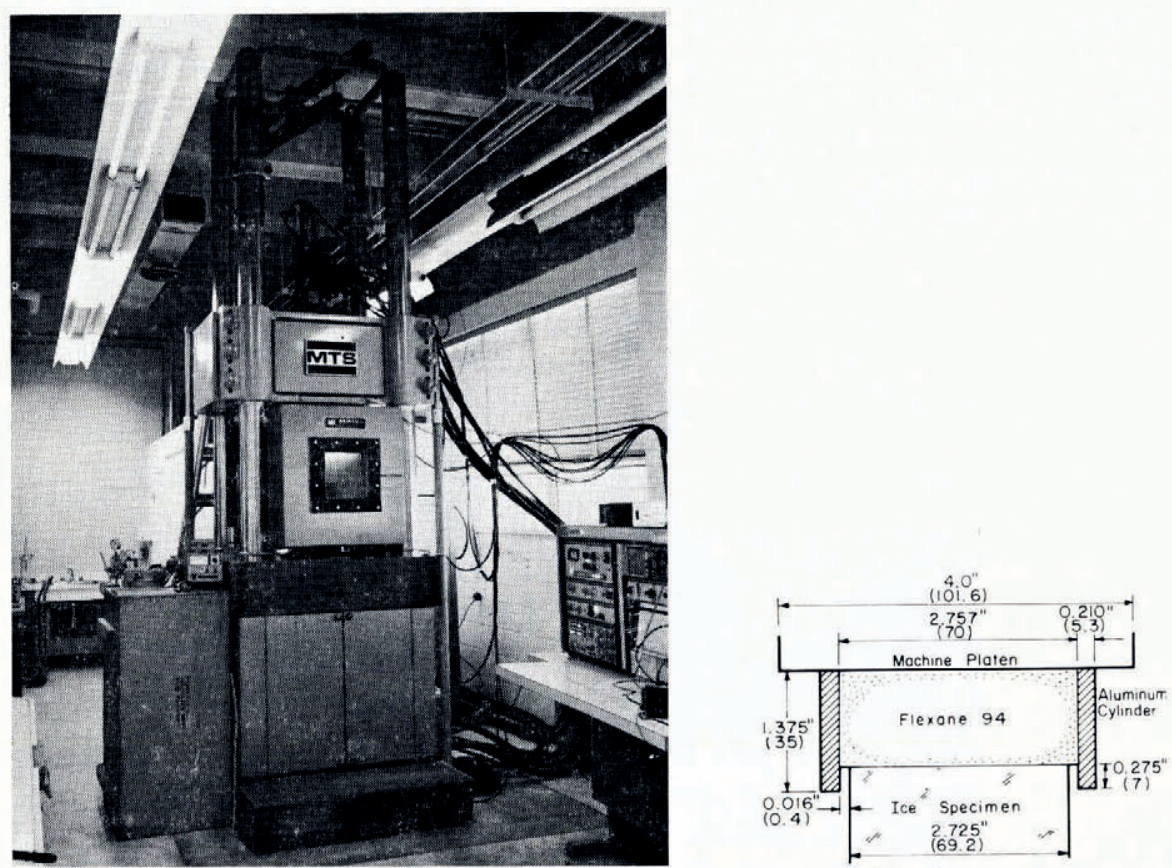

Fig. 2. (left) The MTS testing machine and environmental chamber.

Fig. 3. (right) The compliant platen. Figures in parentheses are millimeters.

\section{TEST APPARATUS AND PROGedURE}

Figure 2 shows the MTS testing machine and the environmental chamber used for the compression tests. The machine has an overall stiffness of the loading system equal to $3.6 \times 10^{8}$ $\mathrm{kg} \mathrm{m}^{-1}$. The hydraulic closed-loop servo system has a response time of $0.5 \mathrm{~ms}$. The environmental chamber is part of a Bemco refrigeration unit capable of maintaining temperatures to within $\pm 0.2^{\circ} \mathrm{C}$ down to $-57^{\circ} \mathrm{C}$. A nominal test temperature of $-9^{\circ} \mathrm{C}$ was used for all tests. A machine speed of $0.042 \mathrm{~m} \mathrm{~s}^{-1}$ was used for the series $\mathrm{I}$ tests and a speed of $0.0042 \mathrm{~m} \mathrm{~s}^{-1}$ was used for the series 2 and series 3 tests.

The platens were made by casting a urethane mix directly in an aluminum cylinder and allowing the mix to cure at room temperature. This urethane has a specific gravity of r. Io and a Shore A hardness of 94 (ASTM D412). After curing, the ends of the urethane were faced off on a lathe with a sharp tool. Bubbles with an average diameter of $\mathrm{I} \mathrm{mm}$ were 
observed on the surface of the urethane. These were caused by air included during the mixing process. Subsequent to the testing conducted in this study a new casting technique was developed. Urethane which is almost bubble-free can be successfully cast using a simple centrifugal method, as described in the Appendix.

The specimens were placed in the urethane compliant platen (Fig. 3) and centered prior to testing. A ball-seat platen, attached to the end of the hydraulic actuator, was positioned to make a no-load contact with the urethane platens. During a test, the load was measured with a MTS model 66r.22 load cell, and recorded on a Tektronix oscilloscope model $\mathrm{R}_{5} \mathrm{IO}_{3} \mathrm{~N}$.

\section{Test Results}

Results for the series I tests are shown in Table I and Figure 4. The average strength for the $2 \mathrm{I}$ tests was $73.8 \mathrm{bar}$, with a ${ }_{13} .6 \%$ maximum deviation from that mean. There was no definite trend over the range of $L / D$ ratios from 0.74 to 2.5 .

TABLe I. RESUlts OF SERIES I COMPRESSION TESTS

\begin{tabular}{|c|c|c|c|c|c|c|}
\hline \multirow[b]{2}{*}{ Specimen } & \multicolumn{5}{|c|}{$\begin{array}{l}\text { Bubbly, polycrystalline ice } \\
\text { Test temperature: }-9.4^{\circ} \mathrm{C} \\
\text { Machine speed: } 0.042^{2} \mathrm{~m} \mathrm{~s}^{-1}\end{array}$} & \multirow[b]{2}{*}{$\begin{array}{l}\text { Maximum } \\
\text { stress } \\
\text { bar }\end{array}$} \\
\hline & $\underset{\mathrm{m} \times 10^{-2}}{L}$ & $\underset{\mathrm{m} \times 10^{-2}}{D}$ & $L / D$ ratio & $\begin{array}{c}\text { Time to } \\
\text { failure } \\
\mathrm{s}\end{array}$ & $\begin{array}{c}\text { Strain- } \\
\text { rate } \\
\mathrm{s}^{-1} \times \mathbf{1}^{-5}\end{array}$ & \\
\hline I & 17.145 & 6.863 & 2.498 & 0.098 & 2.47 & 63.7 \\
\hline 2 & 16.236 & 6.878 & 2.36 & 0.078 & 2.6 & 73.7 \\
\hline 3 & 16.942 & 6.868 & 2.467 & 0.07 & 2.5 & $74 \cdot 4$ \\
\hline 4 & $16.75^{1}$ & 6.909 & 2.425 & 0.074 & 2.53 & 65.3 \\
\hline 5 & 17.272 & $6.9^{22}$ & 2.50 & 0.073 & 2.46 & 78.3 \\
\hline 6 & 8.839 & 6.896 & 1. 28 & 0.071 & 4.8 & 75.6 \\
\hline 7 & $8.80 \mathrm{I}$ & 6.904 & I. 27 & 0.072 & 4.82 & 77.0 \\
\hline 8 & $7 \cdot 988$ & 6.909 & 1. 16 & 0.077 & $5 \cdot 3^{1}$ & 73.5 \\
\hline 9 & 8.534 & 6.896 & I. 24 & 0.066 & 4.97 & 67.5 \\
\hline 10 & 10.587 & 6.914 & I. 53 & 0.072 & 4.0 & 74.6 \\
\hline I I & 10.836 & 6.863 & 1. $5^{8}$ & 0.067 & $3 \cdot 9$ & 74.6 \\
\hline 12 & 7.701 & 6.909 & I. I I & $0.08 \mathrm{I}$ & 5.5 & 75.7 \\
\hline I3 & 7.285 & 6.909 & 1.05 & 0.076 & 5.82 & 82.1 \\
\hline I4 & 8.001 & 6.896 & 1. 16 & 0.068 & $5 \cdot 3$ & 76.8 \\
\hline 15 & 6.642 & 6.888 & $0.9^{6}$ & 0.08 & 6.34 & 77.0 \\
\hline 16 & $5 \cdot 5^{25}$ & 6.858 & $0.8 \mathrm{I}$ & 0.079 & 7.68 & 74.1 \\
\hline 17 & 5.105 & 6.909 & 0.74 & 0.073 & 8.31 & 71.8 \\
\hline 18 & 5.779 & 6.914 & 0.84 & 0.068 & $7 \cdot 34$ & 78.2 \\
\hline 19 & 7.849 & 6.883 & I. 14 & 0.089 & 5.4 & $73 \cdot 5$ \\
\hline 20 & 7.292 & 6.795 & 1.07 & 0.068 & 5.82 & 68.7 \\
\hline 21 & 9.126 & $6.9^{29}$ & I. $3^{2}$ & 0.076 & $\stackrel{4.65}{\mathrm{M}}$ & $\begin{array}{l}73.2 \\
73.78 \mathrm{~b}\end{array}$ \\
\hline
\end{tabular}

Note:

(I) Strain-rate calculations are based on machine speed and time to failure.

(2) Specimen ends were prepared on a lapping plate to a mirror finish.

(3) All specimens were tested with urethane platens.

The series 2 test results are shown in Table II and Figure 5. Nineteen of the 21 tests had an $L / D$ ratio between 2.3 and 2.42 . The measured strength varied from $13 . \mathrm{I}$ to $8 \mathrm{I} .7$ bar depending upon the specimen end preparation and the type of platen used. Table II gives the average values and range for the five specimen end and platen combinations used. There was a $3 \%$ difference between the average values of the lapped and saw-cut specimen ends when tested on urethane platens. However, there was a 1 $6 \%$ difference between average values when similar specimens were tested on steel platens. 


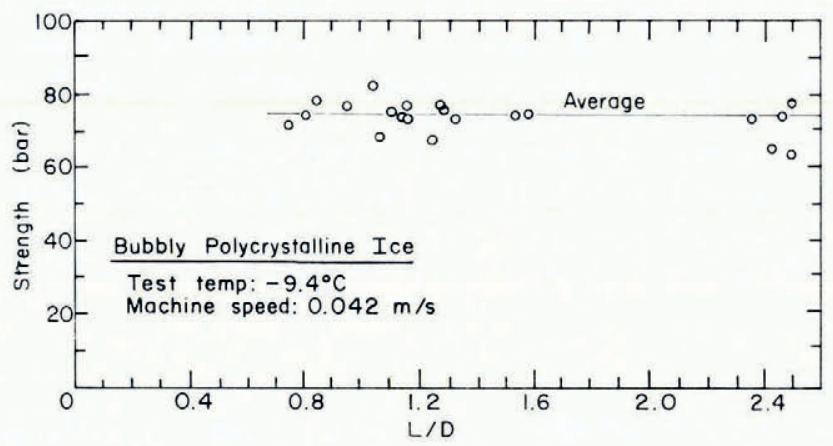

Fig. 4. Strength versus specimen $L / D$ for series I tests using urethane platens.

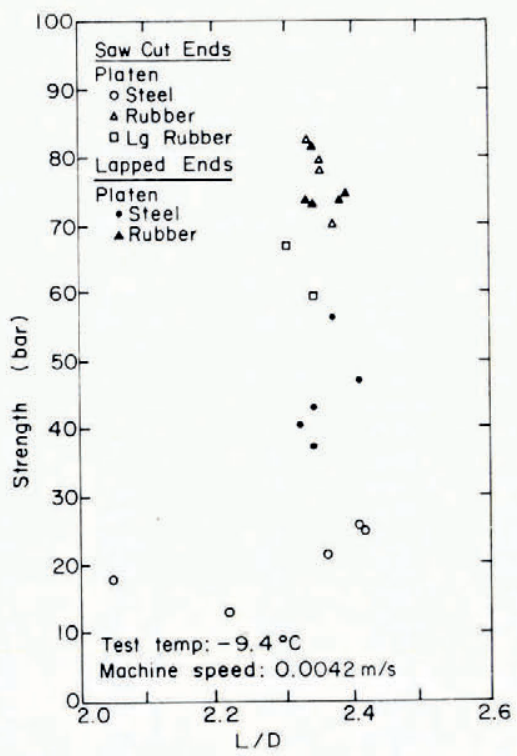

Fig. 5. Strength versus specimen $L / D$ ratio for the series 2 tests using steel, urethane, and large urethane platens.

TABLE II. RESULTS OF SERIES 2 COMPRESSION TESTS

Bubbly, polycrystalline ice

Test temperature: $-9 \cdot 4^{\circ} \mathrm{C}$

Machine speed: $0.0042 \mathrm{~m} \mathrm{~s}^{-1}$

\begin{tabular}{|c|c|c|c|c|c|}
\hline \multirow{2}{*}{$\begin{array}{c}\text { Number of } \\
\text { tests }\end{array}$} & \multirow{2}{*}{$\begin{array}{l}\text { Specimen end } \\
\text { preparation }\end{array}$} & \multirow{2}{*}{$\begin{array}{l}\text { Platen } \\
\text { type }\end{array}$} & \multicolumn{3}{|c|}{ Average compressive strength } \\
\hline & & & $\begin{array}{c}\text { Maximum } \\
\text { bar }\end{array}$ & $\begin{array}{l}\text { Mean } \\
\text { bar }\end{array}$ & $\begin{array}{l}\text { Minimum } \\
\text { bar }\end{array}$ \\
\hline 5 & Saw cut & Steel & 25.7 & 20.6 & I3.I \\
\hline 5 & Lapped & Steel & 56.0 & 44.6 & 37.1 \\
\hline 4 & Saw cut & Urethane & $8 \mathrm{i} .7$ & 76 & 69.6 \\
\hline $\begin{array}{l}\mathbf{T} \\
5\end{array}$ & Lapped & Urethane & $8 \mathrm{r} .0$ & 74.7 & 72.4 \\
\hline${ }_{2}$ & Saw cut & Large urethane & 66.3 & 62.6 & $5^{8.9}$ \\
\hline
\end{tabular}

The large urethane platen had an average annular gap of $0.0043 \mathrm{~m}$ between the sample and the aluminum ring compared with an average gap of $0.0004 \mathrm{~m}$ for the standard urethane platen. 
Table III gives the results of the series 3 tests. Compressive strengths for the 22 tests in this series are plotted in Figure 6. A thin sheet of paper was interposed between the lapped ends of the specimen and the steel platens to reduce stress concentrations caused by possible surface irregularities in the specimen ends. The results show that the compressive strength doubles as the $L / D$ ratio is decreased from 2.2 to 0.6 .

TABle III. Results OF SERIES 3 COMPREssion tests

Polycrystalline ice

Test temperature: $-9.4^{\circ} \mathrm{C}$

Machine speed: $0.0042 \mathrm{~m} \mathrm{~s}^{-1}$

\begin{tabular}{|c|c|c|c|c|}
\hline Specimen & $\underset{\mathrm{m} \times 10^{-2}}{L}$ & $\begin{array}{c}D \\
\mathrm{~m} \times 10^{-2}\end{array}$ & $L / D$ ratio & $\begin{array}{c}\text { Maximum stress } \\
\text { bar }\end{array}$ \\
\hline I & 14.503 & $6.89 \mathrm{I}$ & 2.10 & 39.6 \\
\hline 2 & $\begin{array}{r}12.79 \mathrm{I} \\
\end{array}$ & 6.868 & ז. 86 & 36.6 \\
\hline 3 & 14.072 & 6.883 & 2.04 & 37.0 \\
\hline 4 & 15.519 & 6.922 & 2.24 & $5^{1} \cdot 3$ \\
\hline 5 & 14.910 & 6.896 & 2.16 & $4^{8.2}$ \\
\hline 6 & 1 3.696 & 6.896 & ז.99 & $4^{2} .0$ \\
\hline 7 & 7.137 & 6.909 & 1.03 & 6 ז. \\
\hline 8 & 6.810 & 6.919 & 0.98 & 6 ז. \\
\hline 9 & 7.112 & 6.904 & I.03 & $5^{8.9}$ \\
\hline 10 & 5.969 & 6.909 & 0.86 & 71.4 \\
\hline II & 4.315 & 6.909 & 0.62 & 88.4 \\
\hline 12 & 6.020 & 6.934 & 0.87 & 62.1 \\
\hline 13 & $4.4^{8} 3$ & 6.896 & 0.65 & $64 \cdot 3$ \\
\hline 14 & 9.228 & 6.845 & 1.35 & 60.9 \\
\hline 15 & 10.224 & 6.845 & 1.49 & 63.6 \\
\hline 16 & 8.306 & 6.899 & 1.20 & 54.3 \\
\hline 17 & 5.260 & 6.888 & 0.76 & 64.8 \\
\hline 18 & $\begin{array}{l}5.339 \\
\end{array}$ & 6.896 & 0.77 & 73.2 \\
\hline I9 & 3.975 & 6.901 & 0.58 & 8 o. 8 \\
\hline 20 & 5.588 & 6.914 & $0.8 \mathrm{I}$ & 68.4 \\
\hline $2 \mathrm{I}$ & $\begin{array}{l}3.967 \\
36\end{array}$ & 6.853 & $0.5^{8}$ & 88.9 \\
\hline 22 & 4.524 & 6.845 & 0.66 & 85.4 \\
\hline
\end{tabular}

Steel platens used for all tests.

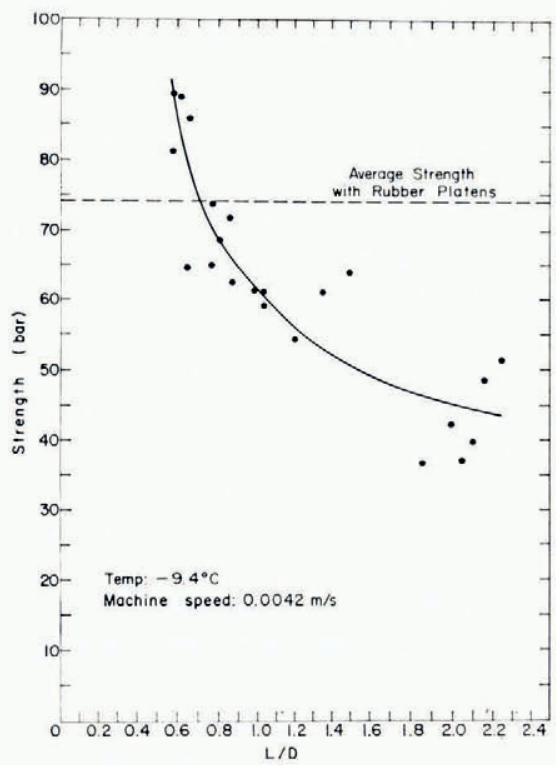

Fig. 6. The relationship of strength of ice to $L / D$ ratio using steel platens. 


\section{Discussion}

Dependence of uniaxial compressive strength on specimen $L / D$ ratio has been discussed by Hawkes and Mellor (1970), Mogi (1966), Newman and Lachance (1964), Obert and Duvall (1967), and Kartashov and others (1970). They all conclude that the apparent strength of rocks tested by the conventional method increases for a $L / D$ ratio less than 2.5 . The explanation for this effect involves the radial restraint produced by a frictional steel platen on the end of the rock specimen. This restraint delays structural failure and enhances the measured strength. Hawkes and Mellor (1970) present results of uniaxial compression tests on various rocks. They point out that apparent compressive strength increases for $L / D$ ratios less than 2.0 and increases very rapidly for $L / D$ ratios less than I.o. They also point out that one way to achieve radial freedom is to match the radial strain in the platen with the radial strain in the test specimen. Matching these radial strains requires that the ratio of Young's modulus to Poisson's ratio $(E / v)$ be the same for both platen and specimen.

Newman and Lachance ( 1964 ) conducted tests on concrete prisms. The apparent compressive strength increased with decreasing $L / D$ ratio when steel platens were used and decreased when a thin $\left(1.6 \times 10^{-3} \mathrm{~m}\right)$ rubber sheet was interposed between the platen and the specimen. They recommend that the capping material for concrete specimens should have the same ratio of Poisson's ratio to the compressive modulus $(\nu / E)$ as the concrete.

Kartashov and others (I970) developed a platen for testing rocks which consisted of a low-modulus insert radially restrained in a high modulus cylindrical yoke. Their tests on rocks showed that the apparent compressive strength increased as $L / D$ decreased for ratios less than 2.5 when high-modulus platens were used. When low-modulus platens were used, the strength decreased as the $L / D$ ratio decreased. However, when the low-modulus insert confined in the cylindrical yoke was used, the strength was essentially constant over an $L / D$ range of 0.5 to 2.75 .

The results of the present investigation indicate that cylindrical specimens of ice may be tested down to an $L / D$ ratio of 0.74 with no apparent effect upon the compressive strength when suitably designed compliant platens are employed. Although Young's modulus for urethane (about $3.8 \times \mathrm{IO}^{2} \mathrm{bar}$ ) is much less than for ice (about $6.9 \times 10^{4} \mathrm{bar}$ ), a confined urethane platen of suitable diameter provides a compatible radial deformation for ice.

Hawkes and Mellor (1970) recommend that specimen ends for rocks should be flat within $2.54^{-12.7} \mu \mathrm{m}$ when testing with steel platens. They further recommend that specimens with a diameter greater than $25.4 \mathrm{~mm}$ should be flat to within $25.4 \mu \mathrm{m}$. Specimens with lapped ends in the present tests had a flatness between 25.4 and $2.54 \mu \mathrm{m}$. However, the specimens with saw-cut ends were flat within about $0.5 \mathrm{~mm}$. The $3 \%$ difference in strength found between the lapped and saw-cut specimens when tested with the urethane platens (Fig. 5) indicates the ability of these platens to remove stress concentrations due to surface irregularities.

The test results confirm that the diametrical clearance between the specimen and the aluminum cylinder is important. Figure 5 shows that the apparent strength decreased when large platens with a diametrical clearance of $6.5 \mathrm{~mm}$ were employed. The optimum design platens had a diametrical clearance of $0.127 \mathrm{~mm}$. This suggests that the large platens experienced radial deformation which induced tensile stresses in the specimen ends and contributed to early failure.

An increase in apparent strength with decreasing $L / D$ ratio when steel platens are used is shown in Figure 6. These results confirm those reported by Hawkes and Mellor (1970), Newman and Lachance (1964) and Kartashov and others (1970). Figure 6 shows the average strength at $L / D$ of 2.2 to be about 42 bar for tests with steel platens. Also shown in Figure 6 is the average strength found with the urethane (rubber) platens (see Table I). These results show good agreement with the results of Hawkes and Mellor (r972). They found the com- 
pressive strength for ice to be considerably lower when right-circular cylindrical specimens were used than when dumb-bell specimens were used. The average strength of ice found with cylindrical specimens and urethane platens in this study is slightly lower than the strength of ice they found with dumb-bell specimens. However, the strain-rate, test temperature and specimen grain size were not exactly the same for the two tests.

The main advantages gained from the use of these platens are: (I) simple procedures are adequate for specimen preparation, and (2) short lengths of core can be utilized. These advantages are of very great significance in field testing where precise technique is not always feasible and the traditional field technique gives highly inaccurate data.

\section{Acknowledgements}

The authors gratefully acknowledge the assistance of many personnel of the U.S. Army Cold Regions Research and Engineering Laboratory, especially Jack Karalius, Robert Bonnett, and Frederick Gernhard.

\section{REFERENCES}

Hawkes, I., and Mellor, M. 1970. Uniaxial testing in rock mechanics laboratories. Engineering Geology, Vol. 4 No. 3, p. $177-285$.

Hawkes, I., and Mellor, M. 1972. Deformation and fracture of ice under uniaxial stress. Journal of Glaciology, Vol. i1, No. 61, p. 103-31.

Kartashov, Yu. M., and others. 1970. Opredeleniye odnoosnogo s'zhsutiya gornykh porod [Determination of the uniaxial compression strengths of rocks]. [By] Yu. M. Kartashov, Yu. D. Mazur-Dzhurilovskiy, A. A. Grokhol'skiy. Fiziko-Technicheskiye Problemy Razrabotki Poleznykh Iskopayemykh, 1970, No. 3, p. 108-10. [English translation in Soviet Mining Science, 1970, No. 3, p. 339-41.]

Mogi, K. 1966. Some precise measurements of fracture strength of rocks under uniform compressive stress. Rock Mechanics Engineering Geology, Vol. 4, No. I, p. 41-55.

Newman, K., and Lachance, L. 1964 . The testing of brittle materials under uniform uniaxial compressive stress. Proceedings American Society for Testing Materials, Vol. 64, p. 1044-67.

Obert, L., and Duvall, W. 1967. Rock mechanics and the design of structures in rock. New York, John Wiley and Sons.

\section{APPENDIX}

\section{Centrifugally-Gast urethane platens}

\section{Casting procedure}

In order to obtain a urethane plug which is bubble free, it was decided that the plug should be cast in a mold which could be rotated at a high angular velocity. The bottom of the mold was aluminum, other parts were made from "Plexiglas" assembled with a finger-tight press fit. The solid-release agent furnished with the urethane was used on the inside of the mold. The aluminum bottom has a recess in it which fits over a bearing attached to a baseplate. After the urethane and curing agent had been thoroughly mixed, the viscous solution was poured into the mold and the top of the mold was set in place. The top has two holes for air removal during the rotation operation. The entire mold was then rotated in a drill press. Rotation caused the mix to ride up the sides of the mold due to centrifugal effects. Air, included during the mixing stage, was separated from the urethane at this time.

After rotation of the mold for I minute at 4200 r.p.m., the speed was steadily reduced to zero over a time interval of two minutes. The top of the mold was then removed and the cast was allowed to cure for $12 \mathrm{~h}$ before total removal from the mold. The urethane slumped down to the bottom of the mold during the curing interval. The mold was dismantled, the plug remained in the short, cylindrical portion of the mold. The plug was then faced off on a lathe and removed from the short "Plexiglas" cylinder. Young's modulus for these plugs, measured in uniaxial compression, was found to be about $3.8 \times 1^{2}$ bar. A Poisson's ratio of 0.45 was obtained for compressive loading.

\section{Assembly of plug and ring}

The first platens were made by casting the urethane plug directly in the aluminum ring. However, when these platens were used in tests at $-10^{\circ} \mathrm{C}$, differential shrinkage caused separation of the plug and the ring. This is explained by the fact that the coefficient of thermal expansion of urethane is about four times that of aluminum. 
In order to solve the problem of separation, it was decided that a shrink-fit technique should be used. The urethane plug was cast with a diameter of $0.07023 \mathrm{~m}$, and the aluminum ring was made with an inside diameter of $0.06972 \mathrm{~m}$. For several hours the plug was kept at a temperature of $-40^{\circ} \mathrm{C}$, while the ring was kept at $+110^{\circ} \mathrm{C}$. At these temperatures the plug diameter was less than the diameter of the ring so that assembly was possible. An interference fit of $0.0003 \mathrm{~m}$ was thereby achieved for a $-10^{\circ} \mathrm{C}$ test temperature.

Essentially, bubble-free urethane can be cast successfully using a simple centrifugal method. Close inspection of a plug after it had been cut in half revealed a small region of bubbles in the center of the plug. The diameter of this region was about $1 \mathrm{~mm}$ and it constituted about $0.02 \%$ of the total plug by volume. Assembly of the urethane plug in an aluminum ring by a shrink-fit technique should prevent separation of the two components when used at low temperatures.

\section{DISCUSSION}

L. W. Gold: Do you consider the flexane platens will still be effective when the ice specimen is subject to ductile deformation?

F. D. Haynes: I would expect so, but for very slow tests the gap might have to be modified. In our experiments approximate strains in the range $10^{-5}$ to $10^{-6}$ were used.

R. Frederking: Have you evaluated these platens over a range of strain-rates? How do you define strain-rate?

HAynes: Our measurements of strain were approximate. We did not test the platens over a range of strain-rates. The primary purpose of these tests was to determine the feasibility of their use for field testing.

B. Michel: How do you measure the real deformation of the ice with such low-modulus plugs?

HAynes: The actual deformation of the ice was not measured; no strain gauges were used. The approximate strain was calculated by using the machine speed and time to failure.

M. Mellor: It has been proved conclusively that measurement of platen displacement introduces significant error into the determination of strain for high-modulus materials. The acceptable techniques involve bonded strain gauges, demountable displacement transducers, or non-contact displacement sensors.

R. L. BRown: How does the Young's modulus of the platen material compare with that of ice for the strain-rates in your experiments?

HAYNEs: The modulus of the urethane is about $4 \times 10^{7} \mathrm{~N} \mathrm{~m}^{-2}$. The modulus of ice is about $7 \times 10^{9} \mathrm{~N} \mathrm{~m}^{-2}$.

P. Tryde: Could you explain the influence of the gap between the specimen and the steel cylinder on the strength?

HAYNEs: If the gap is large (e.g. $5 \mathrm{~mm}$ ), radial tensile stresses will be induced in the specimen ends and result in a lower maximum stress than if the gap is about $0.3 \mathrm{~mm}$. (The specimen diameter is $69.21 \mathrm{~mm}$.)

J. W. GLEN: In removing bubbles from the urethane, why did you centrifuge using an axis of rotation coaxial with the cylinder? If you centrifuge using an axis at right-angles to the axis of the cylinder the material should be pressed into a cylindrical shape at the ends of the mould, rather than climbing the walls of the cylinder and having to drain down into shape again later. This should avoid the small bubbles developing axially in the centre of the resulting plug.

Haynes: This method is worthy of a trial. If enough urethane mix is used it may eliminate the extremely small bubble region. 
D. J. Goodman: Is the author familiar with the paper of Wu and others (1976) who used ice to separate the specimen from the platens? Would he like to comment on this result?

MELLOR: This technique is not really satisfactory. It does not produce "platen matching" unless specimen and cushion diameters are equal, there is a very rough approximation to the dumbbell specimen, but there are still stress perturbations in the specimen.

\section{REFERENCES}

Wu, H. C., and others. 1976. Fracture in the compression of columnar grained ice, by H. C. Wu, K. J. Chang and J. Schwarz. Engineering Fracture Mechanics, Vol. 8, No. 2, p. 365-72. 